\title{
Cumplimiento gubernamental y estilos de gobernar. Análisis de los gobiernos de los municipios semi-urbanos de Michoacán, México
}

\author{
Hugo Amador Herrera Torres y René Colín Martínez \\ Universidad Michoacana de San Nicolás de Hidalgo \\ hugoht@fevaq.net - rcolin@fevaq.net
}

Recibido: 23-08-2014

Aceptado: 01-02-2016

\begin{abstract}
Resumen
Con la construcción y operación de indicadores se calcularon dos índices, uno para determinar el nivel de cumplimiento de los procesos elementales que tienen que realizar los gobiernos de los municipios semiurbanos de Michoacán, y otro para fijar su estilo de gobernar. El índice de cumplimiento gubernamental muestra que estas municipalidades atienden parcialmente la mayoría de sus labores básicas. Su ejercicio prácticamente se da por inercia. El otro índice muestra que siguen trabajando con la visión tradicional de gobernar. Se trata de un estilo donde el protagonismo del alcalde es alto con nulas prácticas estables de participación social. Correlacionando ambos índices, se puede plantear -hasta cierto punto- que el bajo cumplimiento se debe al estilo de gobernar. Los índices además explican que la posición estratégica de semi-urbanidad no es aprovechada por el gobierno para promover otros estilos de gobernar en busca de mejorar su cumplimiento. Diversos grupos ciudadanos -en estos municipios- han formado gobiernos alternativos que sustituyen al gobierno formal, en otros se han constituido gobiernos paralelos.

Palabras claves: gobernanza; gobernación; estilo mixto; cumplimiento gubernamental; gobierno local; municipio semi-urbano.

\section{Governmental Fulfillment and Govern Styles. Analysis of the Governments of the Semi-urban Municipalities of Michoacán, Mexico}

\begin{abstract}
With the creation of indicators and their operation, two indexes were calculated, one to determine the level of fulfillment to the basic governmental processes of semi-urban municipalities in Michoacan, and other to set the govern style. The governmental fulfillment index shows that these municipalities partially serve their basic tasks. Its exercise is almost by inertia. The other index shows that follow the traditional govern style. It is a style where the role of the mayor is high and without stable practices of social cooperation. The correlation of indexes proposes that low fulfillment is by govern style. The results also explain that the strategic position of semi-urban is not used by the government to promote other govern style, looking to improve their fulfillment. Several citizens groups -in these municipalities- formed alternative governments that replace the formal government, others have formed parallel governments.

Key words: governance; govern; mixed style; governmental fulfillment; local government; semi-urban municipality.
\end{abstract}




\section{Referencia normalizada}

Herrera Torres, H.A. y R. Colín Martínez (2016): "Cumplimiento gubernamental y estilos de gobernar", Politica y Sociedad, 53 (1), pp. 143-167.

Sumario: Introducción. 1. Estilos de gobernar: gobernanza, gobernación y forma mixta. 2. Responsabilidades básicas de los gobiernos municipales. 3. Gobernanza y gobiernos de los municipios semi-urbanos. 4. Cumplimiento gubernamental y estilos de gobernar. Evidencia empírica. 5. Conclusiones. 6. Bibliografía.

\section{Introducción}

El gobierno municipal, desde su instauración en México en 1519 por Hernán Cortés, ha sido palanca clave para impulsar cambios en el sistema político del país: sirvieron de base para construir la estructura política del siglo XIX, fueron piezas sustanciales para mantener durante más de 70 años (siglo XX) el esquema de partido político único, en las elecciones de Ayuntamientos se iniciaron los procesos de alternancia política en la década de 1980, que involucraron en el año 2000 al gobierno federal. Los gobiernos municipales representan ahora la modalidad central de la descentralización como producto de las reformas de 1983 y 1999 al artículo 115 constitucional (Merino, 2007: 13-16).

El Estado de Michoacán (una de las entidades federativas de México) está dividido en 113 municipios. Municipios con diferencias marcadas entre sí, diferencias que se expresan en los modos de gobernar. En los gobiernos de los municipios semiurbanos se forman capacidades de gestión especiales porque sus funciones son altamente complejas (López, 2001: 51). Tratan, por un lado, problemas relacionados con materia urbana en la cabecera municipal y, por el otro, asuntos propios de localidades rurales. Esta complejidad en sus gestiones -en vez de considerarse como dificultad- puede aprovecharse como pivote para formar redes de política pública (característica principal de la gobernanza) que permitan dar respuestas desde abajo y en forma organizada a los conflictos sociales del territorio (Herrera, 2011: 138-139). La formación de estas redes puede mejorar el funcionamiento de los gobiernos y -probablemente- puede producir grados aceptables de gobernabilidad en el municipio. La gobernabilidad se asume como consecuencia política directa del funcionamiento del gobierno y refleja escenarios de aceptación social en torno a la gestión de los problemas comunes (Vallès, 2002: 409).

El presente artículo tiene dos objetivos específicos: determinar el nivel de cumplimiento de las responsabilidades elementales de los gobiernos de los municipios semi-urbanos de Michoacán y fijar -en la medida de lo posible- cuál es su estilo de gobernar. El logro de ambos objetivos aporta elementos para conocer -hasta cierto punto- si estos gobiernos están aprovechando su posición de transición entre lo rural y lo urbano en la formación de redes de política pública.

El artículo se divide en cuatro partes. En la primera, se definen diversos estilos de gobernar y se interpretan términos como polity, politics, policy, governance, policy 
networks, policy community e issue networks, que son de uso -más o menos- reciente en los debates teóricos en español sobre hechura de políticas públicas y estilos de gobernar. Estos términos aún no están cerrados y su desarrollo sigue avanzando. En la segunda, se analizan las responsabilidades básicas de los gobiernos locales. En la tercera, se busca explicar el puesto estratégico que tienen los gobiernos de los municipios semi-urbanos en la promoción de procesos de desarrollo, también se procura conectar su posición con la construcción de redes de política pública. Estas tres partes conforman el marco de referencia teórico del artículo. La cuarta parte corresponde a la evidencia empírica: precisar el nivel de cumplimiento de sus responsabilidades operativas mínimas e identificar el estilo con que gobiernan. Resulta obligado subrayar la especificidad y los problemas especiales que tienen los municipios de Michoacán por sus entornos violentos. Al final, se muestran las conclusiones obtenidas y la bibliografía utilizada.

\section{Estilos de gobernar: gobernanza, gobernación y forma mixta}

La política es la actividad colectiva que desarrollan los miembros de una comunidad para atender sus focos conflictivos, los atienden diseñando e implementando acciones (respuestas) con base al marco institucional vigente. Esta definición de política contiene la polity, la politics y la policy. La política como estructura se refiere al entramado institucional que siguen los actores para producir las posibles respuestas que aminoren los problemas sociales. La estructura política corresponde a la polity. La política como proceso anota -de manera particular- la forma de intervención de los actores. Los procesos políticos están en la politics. Las organizaciones gubernamentales son las encargadas de coordinar los procesos políticos. La política como resultado entra en las respuestas dadas a los problemas sociales, respuestas que surgen de la combinación de la estructura (polity) y de los procesos (politics). La política pública es la policy (Vallès, 2002: 45-46). Estos tres elementos permiten el desarrollo sistemático de la política (sistema político).

Elgobernartienesucentroenelprocesopolítico(politics).Paraqueesteprocesoadquiera el calificativo de "político" tiene que desarrollarse atendiendo al cuadro institucional. Lamanera dellevara caboel proceso político precisa sise trata de gobernanza, gobernación o estilo mixto. El concepto de gobernanza (governance) empezó a generalizarse en la década de los noventa, especialmente en la segunda mitad. Ha ido evolucionando. Primero se asociaba al conjunto de acciones realizadas por el gobierno (gobernanza era prácticamente lo mismo que gobernación). La ciudadanía era gobernada, no gobernaba. Ahoraseincluyenyentrelazandemanerainterdependiente-paraatenuarfocosconflictivosactores que comprenden tanto al gobierno como a los diversos grupos ciudadanos . La gobernanza se conceptualizó entonces como un modo bidireccional de gobernar: del gobierno a la ciudadanía y de la ciudadanía al gobierno (Kooiman, 2005). La gobernanza implica la necesidad de definir de manera colectiva y consensuada la priorización de metas, así como los medios para lograrlas (Díaz de León, 2013: 192). La ciudadanía -en la gobernanza- opera mediante redes de política pública (policy networks). 
Las redes de política pública tienen su sustento teórico en el modelo de proceso (1970), presentado en trabajos distintos por Allison, Lindblom, Cohen, March y Olsen y Kingdom, así como en la teoría inter-organizacional (1970) trabajada por Levine y White, Aldrich, Pfeffer, Benson y Crozier (Klinj, 2005). Estas redes están cohesionadas en su operación y tratan de garantizar intervenciones simétricas para sus actores en la construcción de políticas públicas. El gobierno se integra a las redes y, a la vez, funciona como organismo promotor coordinador de éstas, sin adquirir posiciones dominantes. Las redes se organizan horizontalmente, son plurales, con reglas formales e informales. Los actores en las redes se conocen y se reconocen, negocian, intercambian recursos y comparten algunos intereses (Aguilar, 2010; Cabrero, 2007; Prats, 2005; Klijn, 2005; Rhodes, 2005; Mayntz, 2005; Kooiman, 2005; LeGalés y Tatcher, 1995). Las redes de política pública proyectan las acciones de los actores en una lógica transversal que dinamiza las conexiones entre éstos. La conexión configura una dependencia considerable entre los actores.

Las redes de política pública precisan una forma específica de llevar a cabo el proceso político (politics). La deliberación a su interior es fuerte y su influencia sobre las decisiones del gobierno es significativa. Las redes de política pública se refuerzan con redes temáticas (issue networks), que sólo deliberan en momentos determinados, sin tener una estructura clara de organización ni una identificación de actores (Cabrero, 2007: 19).

Las redes de política pública -aun cuando pueden dar estabilidad a la acción del gobierno- no son rígidas, evolucionan y cambian a través del tiempo (Cabrero, 2007: 1920). Rhodes y Marsh (1995) identifican algunos elementos que provocan cambios en la red: a) la dinámica económica, b) la alternancia de partido político en la administración pública, c) las innovaciones tecnológicas, y d) el surgimiento de nuevas instituciones y/o modificación de algunas de ellas.

El concepto de comunidad de política pública (policy community) también hace referencia a la participación de actores vía redes. Pero son redes que se forman por actores específicos, integrados de manera estable (largo plazo), que limitan la incorporación de nuevos miembros, poco flexibles en su operación ordinaria, y cuya deliberación se da estrictamente con base en las reglas formales existentes. La comunidad de política pública parte de las hipótesis de que no todos los intereses tienen la oportunidad de tratarse y que sólo los actores bien organizados y avalados por el gobierno deben jugar un rol importante en la hechura de políticas públicas.

La gobernanza es una expresión de quienes no aceptan como insuperables las deficiencias de la democracia, de quienes han abierto una brecha buscando una gestión más colaborativa y participativa (Oszlak, 2013). Las propuestas de los autores que se conglomeran en esta idea, según Vallès (2002: 124), dan forma al realismo crítico. Se trata de planteamientos que toman como punto de partida la situación actual de la democracia, que proyectan ampliar, ordenar e institucionalizar la intervención de los grupos ciudadanos en los procesos de decisión (redes de política pública). El realismo crítico insiste en la necesidad de reforzar el componente dialogante -o dialéctico- de la democracia, aumentando los momentos de debate entre posiciones y alternativas, sostiene que ésta es una manera viable para evitar la simplificación tecnocrática de los 
expertos, la cual convierte la intervención ciudadana en simple aprobación o rechazo de lo que tales expertos han elaborado previamente.

La gobernación, otra manera de operar el proceso político (politics), consiste en coordinar de manera vertical la interacción gobierno-ciudadanía en la gestión de los conflictos sociales. El proceso político es dirigido por la perspectiva de un solo actor (Klijn, 2005). La principal diferencia entre gobernanza y gobernación está en el tipo de relación gobierno-ciudadano que se forma en el tratamiento de las demandas sociales. En la gobernanza las demandas no se consideran sólo de la ciudadanía, y la gestión no sólo del gobierno, sino que son interdependientes.

La gobernabilidad, por su parte, es el resultado de gobernar, ya sea con la gobernanza, ya sea con la gobernación, ya sea con una combinación de ambas. No obstante, no toda gobernanza ni toda gobernación ni todo estilo mixto llevan necesariamente hacia la gobernabilidad ni tampoco toda gobernabilidad implica desarrollo (Prats, 2005). Cuando los resultados del modo de gobernar son aceptados -de manera regular- entre los grupos ciudadanos puede hablarse de ciertos niveles de gobernabilidad. Rechazos frecuentes y generalizados indican crisis de gobernabilidad: no hay correspondencia satisfactoria entre demandas expresadas y modo de gobernar. Bajos niveles de relación en estas dos variables indican -por lo general- que el modo de gobernar no está generando respuestas (policies) efectivas.

\section{Responsabilidades básicas de los gobiernos municipales}

Atendiendo los 89 instrumentos legales que logra identificar Pérez (2007) con respecto a la organización y regulación de la operación de los gobiernos municipales en la entidad, pero sobre todo, siguiendo la Ley Orgánica Municipal del Estado de Michoacán (uno de los 89 de instrumentos legales) (Congreso del Estado de Michoacán, 2011), se pueden identificar las responsabilidades básicas municipales de cumplimiento obligatorio. Estas responsabilidades se refieren principalmente a la puesta en marcha de procesos. Las variaciones que pudieran presentarse en las responsabilidades serían de forma o aplicación derivadas de la composición interna de los gobiernos locales. Las responsabilidades se agrupan en seis ejes:

1. Reglamentación. Proceso para organizar formalmente la estructura y el funcionamiento de la municipalidad y para normalizar de forma jurídica -manteniendo congruencia con las ordenanzas legales estatales y federales- las actividades de los diversos grupos ciudadanos del municipio.

2. Planeación del desarrollo. Proceso para detectar, interpretar, definir y diseñar los objetivos prioritarios en materia económica, social y política en el municipio.

3. Servicios públicos. Prestaciones orientadas a satisfacer necesidades básicas con eficiencia, calidad y puntualidad: agua potable, drenaje, alcantarillado, tratamiento de aguas residuales, alumbrado público, recolección-traslado-tratamiento de residuos, centrales de abastos, panteones, rastros, calles, parques-jardines, seguridad pública en los términos que marca el artículo 21 de la Constitución Federal, policía preventiva y tránsito. 
4. Hacienda pública. Conjunto de actividades para manejar los recursos patrimoniales y financieros con que cuenta el gobierno local en busca de concretar los objetivos prioritarios municipales.

5. Participación ciudadana. Proceso de involucramiento ciudadano en la toma de decisiones sobre los proyectos que se implementen en el municipio, a fin de consolidar la democracia participativa. Los gobiernos locales deben convocar e intervenir en la constitución y organización de los diversos organismos de participación ciudadana que funcionarán durante del trienio gubernamental. Se abre la posibilidad de promover la intervención ciudadana a través del referéndum, del plebiscito y de la iniciativa popular.

6. Transparencia/rendición de cuentas. Actividades organizadas para informar periódicamente acerca de las acciones, del avance y de los resultados de la operación del gobierno.

Parte considerable de las demandas más sensibles de la ciudadanía se halla en los ejes de planeación del desarrollo y prestación de servicios públicos. Estos dos ejes precisan los resultados mínimos que deben obtenerse (objetivos-metas) y fijan además la manera en que se buscará alcanzar esos resultados, tienen entonces una posición híbrida: determinan a dónde ir (finalidad) y establecen cómo llegar (medios). Los ejes de reglamentación y hacienda pública especifican algunos lineamientos que configuran parte de la manera en que actuará el gobierno. La planeación del desarrollo, la prestación de servicios públicos (ambos en su posición de medios), la reglamentación y el manejo de la hacienda pública se realizan atendiendo los ejes de participación ciudadana y transparencia/rendición de cuentas. Este último eje también debe emprenderse con participación ciudadana. Todos los ejes, en suma, se complementan con la participación ciudadana y operan de forma engranada.

\section{Gobernanza y gobiernos de los municipios semi-urbanos}

Las diferencias socio-económicas existentes entre los municipios también se expresan entre sus gobiernos. Unos tienen mayores capacidades para realizar sus responsabilidades elementales. El tipo de municipio (rural, semi-urbano, urbano, muy urbano) tiene correlación con el tipo de capacidades (Herrera y Colín, 2014). Hay diferencia significativa entre las capacidades que tienen los gobiernos de los municipios muy urbanos y las que tienen los gobiernos de los municipios rurales.

Los gobiernos de los municipios semi-urbanos tienen capacidades de operación particulares, sus funciones son más complejas que las que corresponden a los gobiernos de los municipios rurales, urbanos y muy urbanos (Herrera y Colín, 2014). Los gobiernos de los municipios semi-urbanos, por un lado, intentan resolver problemas sobre urbanización en la cabecera municipal y, por el otro, atienden demandas propias del sector productivo primario en las localidades rurales. La problemática que enfrentan es mixta, en proporción -más o menos- similar. En contraste, los gobiernos de los municipios urbanos y muy urbanos se especializan en la prestación de servicios públicos y en la regulación del uso del suelo. Sus funciones, en una proporción considerable, están dirigidas a una sola dimensión. Los gobiernos de los municipios rurales -de igual 
manera- se especializan (en una proporción considerable) en problemáticas propias de localidades pequeñas y del sector agropecuario (López, 2001: 51).

La problemática mixta que caracteriza a los municipios semi-urbanos complejiza la actuación de sus gobiernos. López (2001: 52-53) lo ejemplifica en dos aspectos:

1. La vivienda en municipios muy urbanos y urbanos no se asume como competencia directa de los gobiernos locales, porque la población tiene acceso a formas de financiamiento vía gobierno federal. En los municipios semi-urbanos, dada la densidad poblacional media-baja y la menor demanda de vivienda, los gobiernos locales deben enfrentar directamente esta situación, no cuentan con el auxilio de organismos federales de vivienda.

2. El crecimiento de la economía de los municipios muy urbanos y urbanos tiene su propia dinámica. El gobierno local actúa como regulador del crecimiento urbano y del ordenamiento espacial de las actividades económicas. En contrapartida, en los municipios semi-urbanos, la intervención de sus gobiernos es menor sobre el crecimiento urbano y mayor sobre la promoción de las actividades económicas.

La problemática mixta de los municipios con definición semi-urbana -aunque implica mayor dificultad para la operación gubernamental- puede aprovecharse como un pivote para generar procesos de desarrollo (Herrera, 2011: 17). En la transición de lo rural hacia lo urbano pueden formarse -con menor grado de conflictividad- roles ciudadanos y gubernamentales sinérgicos que promuevan la creación de redes de política pública. La construcción de redes de política pública no es propia de municipios urbanos y muy urbanos. La gobernanza no es exclusiva de estos municipios. Las gestiones comunitarias tampoco corresponden directamente a los territorios semi-urbanos y rurales. En estos territorios hay instituciones formales, organizaciones gubernamentales oficiales y diversos grupos ciudadanos, por consiguiente, las respuestas políticas a sus problemas tienen la categoría de políticas públicas, incluso, muchas veces estas políticas tienen más grado de públicas que las hechas en los municipios urbanos y muy urbanos.

La gobernanza está experimentando una evolución semántica. Inicialmente se utilizó como sinónimo de gobernación, ahora indica un nuevo estilo de gobernar, distinto al modelo de control jerárquico, incluso, tiene la tendencia a señalar algo más amplio: coordinación de las acciones de los individuos y de las organizaciones para la formación de sociedades. Esta última acepción hace que el campo semántico de la gobernanza no se encasille exclusivamente en la ciencia política, hay indicios de que se convierta en una teoría general de las dinámicas sociales (Prats, 2005: 138). Si el mismo concepto de gobernanza comienza a ser ubicuo, su puesta en marcha -por tantono puede encajonarse a las prácticas de los municipios urbanos y muy urbanos. Esta última aseveración se acentúa más al considerar las características de los municipios semi-urbanos (tamaño y densidad poblacional, por ejemplo).

La construcción y coordinación de redes de política pública se hace menos compleja en los espacios de mediana dimensión, por haber mayor convergencia entre los distintos actores. Lo semi-urbano (también lo rural) constituye espacios para entablar relaciones de cooperación social directa. En este tipo de espacios puede participar la población -con menos barreras- en la definición e implementación de respuestas 
posibles a sus problemas directos, en la elección de sus gobiernos y en la organización de su propia intervención. A diferencia de los municipios urbanos y muy urbanos, en los semi-urbanos hay menores limitaciones para construirse y maniobrar sobre una institucionalidad que tenga más ordenado el quehacer gubernamental mínimo.

La municipalidad semi-urbana cuenta con la oportunidad relativa de bloquear la reproducción del municipio urbano y muy urbano de hoy, cuya institucionalidad es originada generalmente desde arriba. Muchos de los programas implementados por gobiernos de municipios urbanos y muy urbanos son diseñados para desvanecer situaciones no deseadas, producto de la mala planeación socio-económica y/o de factores externos con poco o nulo control sobre ellos. Se trata de programas correctivos. Los gobiernos de municipios semi-urbanos, por su carácter de transición, tienen posibilidad de diseñar programas para evitar escenarios no deseados. Se trata de programas preventivos, productos de la planeación.

\section{Cumplimiento gubernamental y estilos de gobernar. Evidencia empírica}

\subsection{Contexto social, económico y político en los municipios semi-urbanos de Michoacán}

El municipio semi-urbano de Michoacán se caracteriza por tener una población que oscila entre 10,000 y 30,000 habitantes, reunidos en su mayoría en localidades de 5,000 a 15,000 residentes. Su densidad es media-baja. Un porcentaje aceptable de viviendas particulares cuenta con energía eléctrica. La cobertura en drenaje y agua de la red pública también es aceptable. La demanda educativa se cubre satisfactoriamente en el nivel básico y medio superior. La esperanza de vida es cercana a los valores del promedio estatal. La Población Económicamente Ocupada se concentra en actividades terciarias, otra parte -en proporción más o menos similar- labora en actividades primarias, y una pequeña parte en el sector secundario. La mayoría de sus gobiernos reciben ingresos brutos anuales menores a $\$ 40,000,000$ (Herrera, 2011: 105).

El nivel de crecimiento económico alcanzado en estos municipios no ha sido suficiente para dar empleo a una proporción importante de la Población Económicamente Activa, lo que ha ocasionado fuerte migración hacia otros estados de la república mexicana y principalmente hacia Estados Unidos de América (EE. UU.). Michoacán ocupa el cuarto lugar en migración hacia EE. UU. (CONAPO, 2010). La mayoría de los municipios semi-urbanos tiene muy alto y alto grado de intensidad migratoria.

La falta de oportunidades que esta situación conlleva, junto con varios factores más, ha propiciado el surgimiento y la expansión de grupos del crimen organizado: la "Familia Michoacana" y "Los Caballeros Templarios". Éstos han luchado entre sí y contra grupos procedentes de otros estados por la plaza que representa Michoacán, dada su posición estratégica en el trasiego de drogas desde América del Sur hacia EE. UU., a través del puerto de Lázaro Cárdenas. La violencia se exacerbó, se alcanzaron altos niveles de inseguridad. El índice de inseguridad y violencia ciudadana (México Evalúa, 2013) en 2010 fue de 44 para Michoacán (décimo lugar nacional de 32), alcanzando la cifra de 8500 muertes por cada 100 mil habitantes. Esta situación ha 
generado -y continúa generando- hartazgo social. Meses atrás, como consecuencia, aparecieron los "Consejos Ciudadanos de Autodefensa" (grupos armados) (Rivera, 2014: 11), inicialmente en municipios semi-urbanos como Tepalcatepec y Buenavista.

Grupos políticos de Michoacán han tenido una actitud crítica sobre el sistema político nacional. La entidad fue un bastión importante de la Corriente Democrática del Partido Revolucionario Institucional (PRI), transformada después en el Frente Democrático Nacional y posteriormente en el Partido de la Revolución Democrática (PRD), y sigue siendo una plaza electoral fuerte para este partido político. El Partido Revolucionario Institucional (PRI) gobernó durante varias décadas de manera ininterrumpida hasta el 2002. El PRD se alzó con la victoria en las elecciones de 2001 y 2007. El PRI regresó al ejecutivo estatal en 2012, ganó las elecciones de 2011 con el $36.6 \%$ de los votos, seguido del Partido Acción Nacional (PAN) (33.7\%), relegando al PRD al tercer lugar (29.7\%). En los Ayuntamientos, el PAN obtuvo en el proceso electoral de 2011 el $26.9 \%$, el PRI el $45.2 \%$ y el PRD el 27.9\%, sin contar los Ayuntamientos en los que hubo coaliciones entre partidos (Instituto Electoral de Michoacán, 2012: 600-617).

En las votaciones del pasado 7 de junio de 2015, retornó a la gubernatura el PRD con el $35 \%$ de los votos (28\% del PRI y $24 \%$ del PAN). En los Ayuntamientos, el PAN logró el 7.1\%, el PRI el 9.7\% y el PRD el 7.1\%, sin contar aquellos en los que hubo coaliciones entre partidos (Instituto Electoral de Michoacán, 2015). Esto refleja que los grandes partidos (PRD, PAN, PRI) han perdido peso con respecto a los partidos minoritarios. De hecho, por primera vez en Michoacán, un candidato independiente ganó el Ayuntamiento del municipio más grande del estado (la capital de la entidad: Morelia). Contando las coaliciones entre partidos, en estas elecciones (2015), el PRD obtuvo el $45 \%$ de los Ayuntamientos, seguido del PRI con el 35\%. El PAN no formó coaliciones, se quedó con el 7\% (Instituto Electoral de Michoacán, 2015). Estos resultados parecieran mostrar que la población deja de votar mayoritariamente por el partido que en ese momento gobierna, para darle la oportunidad a otro partido que tal vez gobierne mejor, lo cual no ocurre.

\subsection{Universo y muestra de estudio}

De los 113 municipios de Michoacán, 35 tienen definición semi-urbana, que corresponde al 31\% de la totalidad municipal (Herrera, 2011: 100). Estos 35 municipios conforman el universo de estudio. Con el muestreo aleatorio simple estratificado se determinan los municipios que pueden representar al universo de estudio. En este tipo de muestreo, el universo se divide en estratos (regiones para este caso).

En la definición de la muestra, primero se precisa el número de municipios semiurbanos ubicados en cada región $\left(\mathrm{N}_{\mathrm{h}}\right)$ :

1. En la región Lerma-Chapala, 10 de los 17 municipios que la componen son semi-urbanos.

2. Cuitzeo cuenta con 8 municipios con definición semi-urbana. Esta región se forma por 13 municipios.

3. En Tepalcatepec se encuentran 5 municipios con distintivo semi-urbano (hay 10 municipios en esta región). 
4. La región Purépecha está formada por 11 municipios, de los cuales 7 son semiurbanos.

5. El Bajío tiene 2 municipios semi-urbanos.

6. La región Oriente cuenta con un municipio semi-urbano.

7. Pátzcuaro-Zirahuén con uno más.

8. La región Sierra-Costa con otro.

9. Tierra Caliente no presenta municipios con definición semi-urbana.

10. La región Infiernillo tampoco tiene municipios semi-urbanos.

El tamaño de la muestra (n) se fija empleando la fórmula (Anderson, Sweeney y Williams, 2002):

$$
n=\left(\left(\sum_{h=1}^{H} N_{h} S_{h}\right) /\left(N^{2}\left[B^{2} / 4\right]+\sum_{h=1}^{H} N_{h} S_{h}^{2}\right)\right)
$$

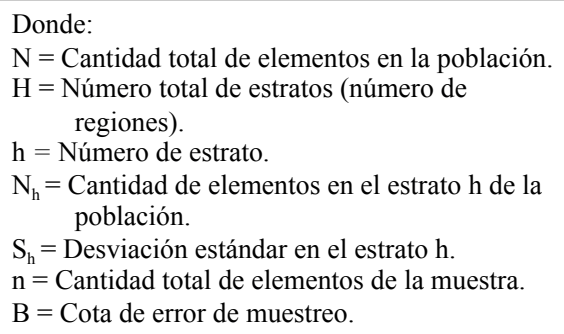

Se asigna -como segundo paso- una fracción (número de municipios semi-urbanos), que se toma como muestra en cada región $\left(n_{h}\right)$. Esta fracción específica el tamaño de la muestra aleatoria simple en cada estrato (región). Los factores que se consideran más importantes en la asignación son: a) cantidad de elementos de cada región, b) varianza de los elementos dentro de cada región, y c) costo de selección de los elementos de cada región. La fórmula para definir el tamaño de la muestra en cada región $\left(\mathrm{n}_{\mathrm{h}}\right)$ es (Anderson, Sweeney y Williams, 2002):

$$
n_{h}=n\left(N_{h} / N\right)
$$

Los resultados obtenidos con la aplicación de la primera y segunda fórmula indican que la muestra se compone por 4 municipios semi-urbanos $(\mathrm{n}=4.175)$. En la región Lerma-Chapala, se encuentra uno de ellos $\left(\mathrm{n}_{\mathrm{h}}=1.193\right)$. El municipio de Purépero es el que presenta los rasgos semi-urbanos más notorios en esta región. En la región Cuitzeo hay otro municipio $\left(\mathrm{n}_{\mathrm{h}}=0.954\right)$ : Tarímbaro, el cual tiene particularidades especiales que obligan a considerarlo: 1) es el municipio más cercano a la capital de la entidad federativa (Morelia), que tiene la mayor tasa de crecimiento demográfico y el mayor dinamismo económico en la entidad. Tarímbaro tiene el peligro latente de quedar envuelto en los movimientos políticos, sociales y económicos de Morelia. 2) Tarímbaro -además- tiene localidades con población semi-urbana y rural, pero el tamaño de su población total y el nivel de su densidad son de corte urbano. Se trata definitivamente de un municipio en transición.

En la región Tepalcatepec, se halla otro municipio que forma parte de la muestra $\left(\mathrm{n}_{\mathrm{h}}\right.$ $=0.596)$. Las características que presenta Cotija lo hacen ser el municipio más semi- 
urbano de este espacio. En la región Purépecha, se localiza el municipio restante $\left(\mathrm{n}_{\mathrm{h}}=\right.$ 0.835). Aquí, Tingambato es el municipio más semi-urbano. El $85 \%$ de los municipios semi-urbanos de Michoacán se localiza en estas 4 regiones. ${ }^{1}$

\subsection{Instrumentos de investigación}

Para la recopilación de información se usaron dos instrumentos de investigación, formados por indicadores que ofrecen datos sobre el estilo de gobernar y el cumplimiento gubernamental. Los indicadores que se consideran en el instrumento sobre estilo de gobernar tratan de fijar la manera en que los gobiernos de los municipios con definición semi-urbana operan los procesos políticos para atender sus responsabilidades básicas (reglamentación, planeación del desarrollo, prestación de servicios públicos, hacienda pública, participación ciudadana y transparencia/rendición de cuentas). Este instrumento intenta mostrar si la municipalidad gobierna de manera tradicional, desde arriba hacia abajo y concentrando las decisiones en el presidente municipal o, si por el contrario, gobierna conforme a la propuesta de gobernanza, estableciendo canales de participación, redes de política pública y mecanismos de transparencia. Los indicadores que se contemplan en el instrumento sobre cumplimiento gubernamental señalan la situación de los municipios en materia de desarrollo y prestación de servicios públicos (dos de las responsabilidades básicas de las municipalidades). El cumplimiento gubernamental no equivale ni refleja propiamente el desempeño global de los gobiernos locales. ${ }^{2,3}$

${ }^{1}$ Utilizar los datos de la totalidad de los municipios semi-urbanos de la entidad, es decir, los datos de todo el universo de estudio, contribuiría de manera significativa a enriquecer los resultados obtenidos. Esta actividad está fuera del alcance del presente trabajo, representa una oportunidad para estudios posteriores.

2 La muestra de estudio contiene margen de error y los indicadores utilizados en los instrumentos de investigación son los mínimos indispensables. El proceso metodológico que se forma con estos dos pasos no debe considerarse entonces como concluyente y definitivo. Para aumentar su confiabilidad es necesario incluir más métodos e indicadores.

${ }^{3}$ Los instrumentos no tienen indicadores sobre aspectos relacionados con temas electorales y proselitistas. Estos temas deben estar separados del ejercicio gubernamental, así como éste de sus resultados. Mezclar temas diversos en un mismo instrumento hace perder precisión en el análisis, también inhibe la posibilidad de estudiar relaciones entre varios temas. La aglutinación de categorías distintas puede otorgar papeles centrales a situaciones/aspectos que no lo son (Cejudo, Sánchez y Zabaleta, 2009: 134). 


\section{Cuadro 1: Indicadores para determinar el estilo de gobernar de los gobiernos de los municipios semi-urbanos de Michoacán}

\begin{tabular}{|c|c|c|c|c|c|c|}
\hline \multirow[t]{2}{*}{ Preguntas } & \multicolumn{5}{|c|}{ Respuestas/Escenarios } & \multirow{2}{*}{$\begin{array}{l}\text { Medios de } \\
\text { verificación }\end{array}$} \\
\hline & 1 & 2 & 3 & 4 & 5 & \\
\hline $\begin{array}{l}1 \text { ¿Cuántas sesiones de cabildo se } \\
\text { realizan por mes en el gobierno } \\
\text { municipal? }\end{array}$ & $\begin{array}{l}\text { Ninguna } \\
\text { sesión }\end{array}$ & 1 sesión & 2 sesiones & 3 sesiones & $\begin{array}{l}4 \text { o más } \\
\text { sesiones }\end{array}$ & -Actas de cabildo. \\
\hline $\begin{array}{l}2 \text { ¿Las Comisiones Colegiadas } \\
\text { del Ayuntamiento cuentan con } \\
\text { programas formales de trabajo? }\end{array}$ & Ninguna & Casi ninguna & Algunas & Casi todas & Todas & $\begin{array}{l}\text {-Programas de } \\
\text { trabajo formales } \\
\text { de las comisiones. }\end{array}$ \\
\hline $\begin{array}{l}3 \text { ¿Cuál es el grado de relación } \\
\text { entre los programas formales } \\
\text { de trabajo de las Comisiones } \\
\text { Colegiadas del Ayuntamiento con } \\
\text { el Plan Municipal de Desarrollo? }\end{array}$ & Muy bajo & Bajo & Regular & Alto & Muy alto & $\begin{array}{l}\text {-Plan Municipal } \\
\text { de Desarrollo. } \\
\text {-Programas de } \\
\text { trabajo formales } \\
\text { de las comisiones. }\end{array}$ \\
\hline $\begin{array}{l}4 \text { ¿El gobierno municipal } \\
\text { para su operación cuenta con } \\
\text { reglamentos de tránsito, policía, } \\
\text { mercados, panteones, catastro, } \\
\text { obras públicas, desarrollo } \\
\text { urbano, limpia, rastro, parques } \\
\text { y jardines, agua, adquisiciones, } \\
\text { protección civil, patrimonio, y } \\
\text { administración interna? }\end{array}$ & $\begin{array}{l}\text { Menos del } \\
70 \%\end{array}$ & $\begin{array}{l}\text { Entre } 70 \mathrm{y} \\
79 \%\end{array}$ & Entre 80 y $89 \%$ & Entre 90 y $99 \%$ & $100 \%$ & $\begin{array}{l}\text {-Reglamentos } \\
\text { municipales. }\end{array}$ \\
\hline $\begin{array}{l}5 \text { ¿El gobierno local cuenta con } \\
\text { reglamento de participación } \\
\text { ciudadana? }\end{array}$ & No & $\begin{array}{l}\text { Sí, pero no } \\
\text { opera }\end{array}$ & $\begin{array}{l}\text { Sí, pero sólo } \\
\text { operan algunos de } \\
\text { sus lineamientos }\end{array}$ & $\begin{array}{l}\text { Sí y opera la } \\
\text { mayoría de sus } \\
\text { lineamientos }\end{array}$ & $\begin{array}{l}\text { Sí y operan } \\
\text { todos sus } \\
\text { lineamientos }\end{array}$ & $\begin{array}{l}\text {-Reglamento de } \\
\text { participación } \\
\text { ciudadana. } \\
\text {-Reporte de } \\
\text { actividades. }\end{array}$ \\
\hline $\begin{array}{l}6 \text { ¿Hace cuánto fue la última } \\
\text { revisión de los reglamentos } \\
\text { municipales? }\end{array}$ & $\begin{array}{l}\text { Más de } 12 \\
\text { años }\end{array}$ & $10-12$ años & $8-10$ años & $6-8$ años & $\begin{array}{l}\text { Menos de } 6 \\
\text { años }\end{array}$ & -Reglamentos. \\
\hline
\end{tabular}




\begin{tabular}{|c|c|c|c|c|c|c|}
\hline \multirow[t]{2}{*}{ Preguntas } & \multicolumn{5}{|c|}{ Respuestas/Escenarios } & \multirow{2}{*}{$\begin{array}{l}\text { Medios de } \\
\text { verificación }\end{array}$} \\
\hline & 1 & 2 & 3 & 4 & 5 & \\
\hline $\begin{array}{l}7 \text { ¿Grado de participación } \\
\text { ciudadana en la elaboración y/o } \\
\text { revisión de los reglamentos? }\end{array}$ & $\begin{array}{l}\text { Sin } \\
\text { participación } \\
\text { ciudadana }\end{array}$ & $\begin{array}{l}\text { Baja y } \\
\text { desorganizada } \\
\text { participación } \\
\text { ciudadana }\end{array}$ & $\begin{array}{l}\text { Bala participación } \\
\text { ciudadana, pero } \\
\text { ordenada } \\
\text { Alta participación } \\
\text { ciudadana, pero } \\
\text { desorganizada }\end{array}$ & $\begin{array}{l}\text { Alta y ordenada } \\
\text { participación } \\
\text { ciudadana }\end{array}$ & $\begin{array}{l}\text { Redes de } \\
\text { política pública }\end{array}$ & $\begin{array}{l}\text {-Reporte de } \\
\text { actividades. }\end{array}$ \\
\hline $\begin{array}{l}8 \text { ¿Grado de participación } \\
\text { ciudadana en la elaboración del } \\
\text { Plan de Desarrollo Municipal? }\end{array}$ & $\begin{array}{l}\text { Sin } \\
\text { participación } \\
\text { ciudadana }\end{array}$ & $\begin{array}{l}\text { Baja y } \\
\text { desorganizada } \\
\text { participación } \\
\text { ciudadana }\end{array}$ & $\begin{array}{l}\text { Bala participación } \\
\text { ciudadana, pero } \\
\text { ordenada } \\
\text { Alta participación } \\
\text { ciudadana, pero } \\
\text { desorganizada }\end{array}$ & $\begin{array}{l}\text { Alta y ordenada } \\
\text { participación } \\
\text { ciudadana }\end{array}$ & $\begin{array}{l}\text { Redes de } \\
\text { política pública }\end{array}$ & $\begin{array}{l}\text {-Reporte de } \\
\text { actividades. }\end{array}$ \\
\hline $\begin{array}{l}9 \text { ¿Los programas operativos } \\
\text { anuales contienen metas que } \\
\text { indiquen lo que se quiere } \\
\text { obtener (cantidad), con cuánto } \\
\text { presupuesto y en cuánto tiempo? }\end{array}$ & Sin metas & $\begin{array}{l}\text { Con metas, } \\
\text { pero sin } \\
\text { especificar } \\
\text { cantidad, } \\
\text { presupuesto y } \\
\text { tiempo }\end{array}$ & $\begin{array}{l}\text { Con metas, } \\
\text { señalando sólo un } \\
\text { elemento }\end{array}$ & $\begin{array}{l}\text { Con metas, } \\
\text { señalando dos } \\
\text { elementos }\end{array}$ & $\begin{array}{l}\text { Con metas, } \\
\text { especificando } \\
\text { cantidad, } \\
\text { presupuesto y } \\
\text { tiempo }\end{array}$ & $\begin{array}{l}\text {-Programas } \\
\text { operativos } \\
\text { anuales. }\end{array}$ \\
\hline $\begin{array}{l}10 \text { ¿Los programas operativos } \\
\text { anuales contienen metas sobre } \\
\text { cobertura de agua potable } \\
\text { señalando población beneficiada, } \\
\text { presupuesto y tiempo? }\end{array}$ & Sin metas & $\begin{array}{l}\text { Con metas, } \\
\text { pero sin } \\
\text { especificar } \\
\text { población } \\
\text { beneficiada, } \\
\text { presupuesto y } \\
\text { tiempo }\end{array}$ & $\begin{array}{l}\text { Con metas, } \\
\text { señalando sólo un } \\
\text { elemento }\end{array}$ & $\begin{array}{l}\text { Con metas, } \\
\text { señalando dos } \\
\text { elementos }\end{array}$ & $\begin{array}{l}\text { Con metas, } \\
\text { especificando } \\
\text { población } \\
\text { beneficiada, } \\
\text { presupuesto y } \\
\text { tiempo }\end{array}$ & $\begin{array}{l}\text {-Programas } \\
\text { operativos } \\
\text { anuales. }\end{array}$ \\
\hline $\begin{array}{l}\text { 11. ¿Los programas operativos } \\
\text { anuales tienen metas sobre } \\
\text { cobertura de drenaje y } \\
\text { alcantarillado señalando } \\
\text { población beneficiada, } \\
\text { presupuesto y tiempo? }\end{array}$ & Sin metas & $\begin{array}{l}\text { Con metas, } \\
\text { sin especificar } \\
\text { población } \\
\text { beneficiada, } \\
\text { presupuesto y } \\
\text { tiempo }\end{array}$ & $\begin{array}{l}\text { Con metas, } \\
\text { señalando sólo un } \\
\text { elemento }\end{array}$ & $\begin{array}{l}\text { Con metas, } \\
\text { señalando dos } \\
\text { elementos }\end{array}$ & $\begin{array}{l}\text { Con metas, } \\
\text { especificando } \\
\text { población } \\
\text { beneficiada, } \\
\text { presupuesto y } \\
\text { tiempo }\end{array}$ & $\begin{array}{l}\text {-Programas } \\
\text { operativos } \\
\text { anuales. }\end{array}$ \\
\hline
\end{tabular}




\begin{tabular}{|c|c|c|c|c|c|c|}
\hline \multirow[t]{2}{*}{ Preguntas } & \multicolumn{5}{|c|}{ Respuestas/Escenarios } & \multirow{2}{*}{$\begin{array}{l}\text { Medios de } \\
\text { verificación }\end{array}$} \\
\hline & 1 & 2 & 3 & 4 & 5 & \\
\hline $\begin{array}{l}12 \text { ¿Cuál es el nivel de esfuerzo } \\
\text { tributario en el municipio } \\
\text { (ingresos propios/ingresos } \\
\text { propios)? }\end{array}$ & $\begin{array}{l}\text { Muy bajo } \\
\text { (menos de } \\
0.20 \text { ) }\end{array}$ & $\begin{array}{l}\text { Bajo } \\
\text { (entre } 0.20 \mathrm{y} \\
0.28 \text { ) }\end{array}$ & $\begin{array}{l}\text { Medio } \\
\text { (entre } 0.29 \text { y } 0.37 \text { ) }\end{array}$ & $\begin{array}{l}\text { Alto } \\
\text { (entre } 0.38 \mathrm{y} \\
0.46)\end{array}$ & $\begin{array}{l}\text { Muy alto } \\
\text { (mayor a } 0.46 \text { ) }\end{array}$ & $\begin{array}{l}\text {-Estado de Origen } \\
\text { y Aplicación de } \\
\text { Recursos Anual. }\end{array}$ \\
\hline $\begin{array}{l}13 \text { ¿Cómo se considera la } \\
\text { relación de los Presupuestos } \\
\text { Municipales de Egresos anuales } \\
\text { con el Plan Municipal de } \\
\text { Desarrollo? }\end{array}$ & Muy baja & Baja & Media & Alta & Muy alta & $\begin{array}{l}\text {-Plan Municipal } \\
\text { de Desarrollo. } \\
\text {-Presupuestos } \\
\text { Municipales de } \\
\text { Egresos. }\end{array}$ \\
\hline $\begin{array}{l}14 \text { ¿Cuál es el cumplimiento } \\
\text { del Presupuesto Municipal de } \\
\text { Egresos? }\end{array}$ & $\begin{array}{l}\text { Menos del } \\
70 \%\end{array}$ & $\begin{array}{l}\text { Entre } 70 \mathrm{y} \\
78.33 \%\end{array}$ & $\begin{array}{l}\text { Entre } 78.34 \text { y } \\
86.66 \%\end{array}$ & $\begin{array}{l}\text { Entre } 86.67 \text { y } \\
95 \%\end{array}$ & Más del 95\% & $\begin{array}{l}\text {-Presupuesto } \\
\text { Municipal de } \\
\text { Egresos. } \\
\text {-Estado de Origen } \\
\text { y Aplicación de } \\
\text { Recursos Anual. }\end{array}$ \\
\hline $\begin{array}{l}15 \text { ¿Grado de participación } \\
\text { ciudadana en la elaboración del } \\
\text { Presupuesto de Egresos? }\end{array}$ & $\begin{array}{l}\text { Sin } \\
\text { participación } \\
\text { ciudadana }\end{array}$ & $\begin{array}{l}\text { Baja y } \\
\text { desorganizada } \\
\text { participación } \\
\text { ciudadana }\end{array}$ & $\begin{array}{l}\text { Bala participación } \\
\text { ciudadana, pero } \\
\text { ordenada } \\
\text { Alta participación } \\
\text { ciudadana, pero } \\
\text { desorganizada }\end{array}$ & $\begin{array}{l}\text { Alta y ordenada } \\
\text { participación } \\
\text { ciudadana }\end{array}$ & $\begin{array}{l}\text { Redes de } \\
\text { política pública }\end{array}$ & $\begin{array}{l}\text {-Reporte de } \\
\text { actividades. }\end{array}$ \\
\hline $\begin{array}{l}16 \text { ¿Existen órganos responsables } \\
\text { de la comunicación social en el } \\
\text { gobierno municipal? }\end{array}$ & No existen & $\begin{array}{l}\text { Existen, pero } \\
\text { no operan }\end{array}$ & $\begin{array}{l}\text { Existen, } \\
\text { pero operan } \\
\text { insuficientemente }\end{array}$ & $\begin{array}{l}\text { Existen y casi } \\
\text { siempre operan } \\
\text { suficientemente }\end{array}$ & $\begin{array}{l}\text { Existen y } \\
\text { siempre operan } \\
\text { suficientemente }\end{array}$ & $\begin{array}{l}\text {-Organigrama. } \\
\text {-Plan de trabajo. }\end{array}$ \\
\hline $\begin{array}{l}17 \text { ¿El gobierno municipal hace } \\
\text { públicos en forma y tiempo los } \\
\text { siguientes documentos: } \\
\text { 1. Cuenta Pública Municipal. } \\
\text { 2. Plan Municipal de Desarrollo. } \\
\text { 3. Presupuesto Municipal de } \\
\text { Egresos. } \\
\text { 4. Presupuesto (estimación) de } \\
\text { Ingresos Municipales. } \\
\text { 5. Ley de Ingresos Municipal. } \\
\text { 6. Reglamentos Municipales. } \\
\text { 7. Estado de Origen y Aplicación } \\
\text { de Recursos Públicos. } \\
\text { 8. Informe del Ejercicio Anual } \\
\text { Municipal? }\end{array}$ & $\begin{array}{l}\text { Menos de } 5 \\
\text { documentos }\end{array}$ & 5 documentos & 6 documentos & 7 documentos & 8 documentos & $\begin{array}{l}\text {-Documentos } \\
\text { publicados. }\end{array}$ \\
\hline
\end{tabular}




\begin{tabular}{|c|c|c|c|c|c|c|}
\hline \multirow[t]{2}{*}{ Preguntas } & \multicolumn{5}{|c|}{ Respuestas/Escenarios } & \multirow{2}{*}{$\begin{array}{l}\text { Medios de } \\
\text { verificación }\end{array}$} \\
\hline & 1 & 2 & 3 & 4 & 5 & \\
\hline $\begin{array}{l}18 \text { ¿Grado de participación } \\
\text { ciudadana en la elaboración } \\
\text { de los documentos que deben } \\
\text { publicarse de manera oficial? }\end{array}$ & $\begin{array}{l}\text { Sin } \\
\text { participación } \\
\text { ciudadana }\end{array}$ & $\begin{array}{l}\text { Baja y } \\
\text { desorganizada } \\
\text { participación } \\
\text { ciudadana }\end{array}$ & $\begin{array}{l}\text { Bala participación } \\
\text { ciudadana, pero } \\
\text { ordenada } \\
\text { Alta participación } \\
\text { ciudadana, pero } \\
\text { desorganizada }\end{array}$ & $\begin{array}{l}\text { Alta y ordenada } \\
\text { participación } \\
\text { ciudadana }\end{array}$ & $\begin{array}{l}\text { Redes de } \\
\text { política pública }\end{array}$ & $\begin{array}{l}\text {-Reporte de } \\
\text { actividades. }\end{array}$ \\
\hline
\end{tabular}

Fuente: Elaboración propia con base en Herrera (2011) y Sánchez, Tovar y Sánchez (2003).

Los indicadores de ambos instrumentos están constituidos por tres partes: parámetro de medición, métrica de medición y medio de verificación. El parámetro de medición corresponde al aspecto clave que se desea analizar (véase cuadro 1 y 2). El instrumento de investigación -en su conjunto- no es extrapolable para otros objetos de estudio similares. Para los gobiernos de los municipios rurales, urbanos o muy urbanos sería necesario disminuir o aumentar los aspectos, ya que tienen condiciones de operación distintas (aplica para los dos instrumentos). La métrica de medición enumera cinco respuestas/escenarios, sigue una escala tipo Likert (véase cuadro 1 y 2). Los valores fijados en las respuestas/escenarios conciernen a las características de los gobiernos de los municipios semi-urbanos. Esto hace, en conjunto con los parámetros de medición, que los instrumentos de investigación sean de aplicación exclusiva para este tipo de gobiernos. Para ajustarlos a gobiernos de municipios rurales, urbanos o muy urbanos se requeriría cambiar los valores fijados en las respuestas/escenarios de los aspectos que se analizan. Los medios de verificación permiten colocar el aspecto a medir en un escenario específico. ${ }^{4}$

${ }^{4}$ La mayoría de los indicadores tienen un medio de verificación soportado en bases de datos oficiales y en documentos de publicación obligatoria por el gobierno municipal. Hay otros que de manera inevitable se basan en reportes internos de actividades. Esto último disminuye el grado de confiabilidad de los instrumentos de investigación. 
Cuadro 2: Indicadores para determinar el cumplimiento gubernamental en los municipios semi-urbanos de Michoacán

\begin{tabular}{|c|c|c|c|c|c|c|}
\hline \multirow[t]{2}{*}{ Preguntas } & \multicolumn{5}{|c|}{ Respuestas/Escenarios } & \multirow{2}{*}{$\begin{array}{l}\text { Medios de } \\
\text { verificación }\end{array}$} \\
\hline & 1 & 2 & 3 & 4 & 5 & \\
\hline $\begin{array}{l}1 \text { ¿Cuál es el nivel de ingreso } \\
\text { per-cápita en el municipio? }\end{array}$ & $\begin{array}{l}\text { Muy bajo } \\
\text { (menos de } \\
0.6225 \text { ) }\end{array}$ & $\begin{array}{l}\text { Bajo } \\
\text { (entre } 0.6225 \mathrm{y} \\
0.6425 \text { ) }\end{array}$ & $\begin{array}{l}\text { Medio } \\
\text { (entre } 0.6426 \mathrm{y} \\
0.6626)\end{array}$ & $\begin{array}{l}\text { Alto } \\
\text { (entre } 0.6227 \mathrm{y} \\
0.6827 \text { ) }\end{array}$ & $\begin{array}{l}\text { Muy alto } \\
\text { (más de } 0.6827 \text { ) }\end{array}$ & $\begin{array}{l}\text {-Índice de } \\
\text { ingresos } \\
\text { municipal, } \\
\text { PNUD. }\end{array}$ \\
\hline $\begin{array}{l}2 \text { ¿Cuál es el nivel de } \\
\text { educación en el municipio? }\end{array}$ & $\begin{array}{l}\text { Muy bajo } \\
\text { (menos de } \\
0.7356)\end{array}$ & $\begin{array}{l}\text { Bajo } \\
\text { (entre } 0.7356 \mathrm{y} \\
0.7574 \text { ) }\end{array}$ & $\begin{array}{l}\text { Medio } \\
\text { (entre } 0.7576 \text { y } \\
0.7795)\end{array}$ & $\begin{array}{l}\text { Alto } \\
\text { (entre } 0.7796 \mathrm{y} \\
0.8016 \text { ) }\end{array}$ & $\begin{array}{l}\text { Muy alto } \\
\text { (más de } 0.8016 \text { ) }\end{array}$ & $\begin{array}{l}\text {-Índice de } \\
\text { educación } \\
\text { municipal, } \\
\text { PNUD. }\end{array}$ \\
\hline $\begin{array}{l}3 \text { ¿Cuál es el nivel de salud en } \\
\text { el municipio? }\end{array}$ & $\begin{array}{l}\text { Muy bajo } \\
\text { (menos de } \\
0.7143 \text { ) }\end{array}$ & $\begin{array}{l}\text { Bajo } \\
\text { (entre } 0.7143 \mathrm{y} \\
0.7502)\end{array}$ & $\begin{array}{l}\text { Medio } \\
\text { (entre } 0.7503 \mathrm{y} \\
0.7862 \text { ) }\end{array}$ & $\begin{array}{l}\text { Alto } \\
\text { (entre } 0.7863 \mathrm{y} \\
0.8223 \text { ) }\end{array}$ & $\begin{array}{l}\text { Muy alto } \\
\text { (más de } 0.8223 \text { ) }\end{array}$ & $\begin{array}{l}\text {-Índice de salud } \\
\text { municipal, } \\
\text { PNUD. }\end{array}$ \\
\hline $\begin{array}{l}5 \text { ¿Cuántos policías por cada } \\
2000 \text { habitantes tiene el } \\
\text { municipio? }\end{array}$ & 1 & 2 & 3 & 4 & 5 & $\begin{array}{l}\text {-Tabulador } \\
\text { de sueldos y } \\
\text { salarios. } \\
\text {-Censo General } \\
\text { de Población y } \\
\text { Vivienda. }\end{array}$ \\
\hline $\begin{array}{l}6 \text { ¿Cuál es el avance del Plan } \\
\text { Municipal de Desarrollo al } \\
\text { segundo ejercicio anual de } \\
\text { cuatro ejercicios anuales? }^{*}\end{array}$ & Menos del 25\% & $\begin{array}{l}\text { Entre } 25 \mathrm{y} \\
33.33 \%\end{array}$ & $\begin{array}{l}\text { Entre } 33.32 \text { y } \\
41.66 \%\end{array}$ & $\begin{array}{l}\text { Entre } 41.65 \mathrm{y} \\
50 \%\end{array}$ & Más del $50 \%$ & $\begin{array}{l}\text {-Plan Municipal } \\
\text { de Desarrollo. } \\
\text {-Programas } \\
\text { operativos } \\
\text { anuales. } \\
\text {-Metas logradas. }\end{array}$ \\
\hline $\begin{array}{l}7 \text { ¿Cuántas viviendas cuentan } \\
\text { con agua potable en el } \\
\text { municipio? }\end{array}$ & Menos 59.99\% & $\begin{array}{l}\text { Entre } 59.99 \mathrm{y} \\
72.97 \%\end{array}$ & $\begin{array}{l}\text { Entre } 66.49 \mathrm{y} \\
72.98 \%\end{array}$ & $\begin{array}{l}\text { Entre } 72.99 \mathrm{y} \\
79.49 \%\end{array}$ & Más del 79.49\% & $\begin{array}{l}\text {-Censo General } \\
\text { de Población y } \\
\text { Vivienda. }\end{array}$ \\
\hline $\begin{array}{l}8 \text { ¿Cuántas viviendas cuentan } \\
\text { con drenaje y alcantarillado en } \\
\text { el municipio? }\end{array}$ & Menos $41.37 \%$ & $\begin{array}{l}\text { Entre } 41.37 \mathrm{y} \\
50.64 \%\end{array}$ & $\begin{array}{l}\text { Entre } 50.65 \mathrm{y} \\
59.92 \%\end{array}$ & $\begin{array}{l}\text { Entre } 59.93 \mathrm{y} \\
69.61 \%\end{array}$ & Más del 69.61\% & $\begin{array}{l}\text {-Censo General } \\
\text { de Población y } \\
\text { Vivienda. }\end{array}$ \\
\hline
\end{tabular}

Fuente: Elaboración propia con base en Herrera (2011) y Flamand, Martínez y Hernández (2007).

* El periodo gubernamental analizado contempla cuatro años por situación extraordinaria, se buscan elecciones concurrentes en Michoacán.

\subsection{Análisis e interpretación de datos}

El análisis de los datos requiere del cálculo de dos índices: Índice de Estilo de Gobernar (IEG) e Índice sobre Cumplimiento Gubernamental (ICG). El IEG -en sí- representa el nivel de gobernanza alcanzado por una municipalidad. Los índices representan una ponderación agregada de los indicadores. El IEG incluye 18 indicadores, mientras que el (ICG) consta de 8. El proceso metodológico que se emplea en ambos índices es igual. En el cálculo de éstos se consideró una ponderación equiproporcional (Schuschny y Soto, 2009). 
Siguiendo la metodología, primero se obtienen el IEG y el ICG para cada gobierno municipal muestra de estudio. En total serían 8 índices municipales, dos por cada municipalidad. Para estimar cada uno de estos, se empieza asignando un valor a los indicadores enlistados en los instrumentos de investigación. Los valores se basan en una escala tipo Likert, van del 1 al 5 (métrica de medición). Luego se calcula el índice por cada municipio (IEG municipal - ICG municipal): la sumatoria de los puntos obtenidos en los indicadores entre la sumatoria del máximo de puntos que es posible obtener en los indicadores (90 para el IEG y 40 para el ICG). Expresado en fórmulas sería:

$$
\begin{aligned}
& I E G \text { municipal }=\frac{\sum_{1}^{18} \text { valor del indicador }}{\sum_{1}^{18} \text { valor máximo del indicador }} \\
& \text { ICG municipal }=\frac{\sum_{1}^{8} \text { valor del indicador }}{\sum_{1}^{8} \text { valor máximo del indicador }}
\end{aligned}
$$

Tanto el IEG como el ICG del conjunto de los gobiernos de los municipios semi-urbanos de Michoacán (IEG msu - ICG msu) equivalen al promedio de los índices municipales: ${ }^{5}$

$$
\begin{aligned}
& I E G m s u=\frac{\sum_{1}^{4} \text { IEG municipal }}{4} \\
& I C G m s u=\frac{\sum_{1}^{4} \text { ICG municipal }}{4}
\end{aligned}
$$

Ambos índices se clasifican en una escala dividida en cinco escenarios (escala tipo Likert) (véase cuadro 3).

El periodo de análisis corresponde al ejercicio municipal 2008-2011. En Cotija, el gobierno era de afiliación panista (PAN), para el periodo 2012-2015 se mantuvo la misma afiliación, en las elecciones de junio de 2015 ganó el Partido Verde Ecologista, la nueva gestión comprenderá el periodo 2016-2018; en Purépero, la municipalidad era de extracción perredista, en el presente ejercicio está el Partido del Trabajo (PT), en 2015 obtuvo la mayoría de votos el Partido Nueva Alianza; en Tarímbaro gobernaba el PRD, el presidente municipal ocupaba por tercera vez ese puesto, ahora gobierna el PRI, en 2015 volvió a ganar el presidente que ya había estado tres veces, comienza su cuarta gestión municipal en enero de 2016, fue postulado por la coalición formada por el PT y el Partido Encuentro Social; en Tingambato, el gobierno era de procedencia priísta, en el actual ejercicio se encuentra el PRD en alianza con Convergencia, en junio

${ }^{5}$ El procedimiento metodológico para obtener el IEG y el ICG tiene algunos vínculos con el índice de competitividad de las ciudades de México de Cabrero y Orihuela (2012: 17-60), con el índice de desarrollo municipal básico de Flamand, Martínez y Hernández (2007), y con el índice de desempeño de los gobiernos municipales de Sánchez, Tovar y Sánchez (2003: 55-72). 
de 2015 se alzó nuevamente con la victoria electoral el PRD, ahora en alianza con el PT y con el Partido Nueva Alianza (Instituto Electoral de Michoacán, 2015). En los cuatro municipios analizados la alternancia partidista ha sido alta.

\subsubsection{Estilo de gobernar de los gobiernos municipales semi-urbanos de Michoacán}

La gobernanza es baja en Tarímbaro (IEG municipal $=0.48$ ), en Cotija también (0.37), al igual que en Purépero (0.37). En Tingambato es muy baja (0.31). El IEG msu es de 0.38 , que equivale a una gobernanza baja (véase cuadro 3 ). ${ }^{6}$ Estos gobiernos tienen pocos elementos de gestión participativa para cumplir con sus competencias elementales, además no fomentan la formación de redes de políticas públicas, siguen con la visión tradicional de gobernar (gobernación), anulando las perspectivas integrales, donde el bien común pueda asumirse como un compromiso conjunto.

Cuadro 3: Clasificación del IEG msu

\begin{tabular}{|c|c|c|c|c|}
\hline $\begin{array}{c}\text { Gobernanza } \\
\text { muy baja }\end{array}$ & $\begin{array}{c}\text { Gobernanza } \\
\text { baja }\end{array}$ & $\begin{array}{c}\text { Gobernanza } \\
\text { regular }\end{array}$ & $\begin{array}{c}\text { Gobernanza } \\
\text { alta }\end{array}$ & $\begin{array}{c}\text { Gobernanza } \\
\text { muy alta }\end{array}$ \\
\hline 0.20 & \multicolumn{2}{|c|}{0.68} & & 0.84 \\
\hline
\end{tabular}

0.38

Fuente: Elaboración propia con base en la investigación documental y de campo.

El 0.62 que falta para que estos gobiernos se acerquen a una gobernanza muy alta (IEG $m s u=1.00$ ) puede explicarse por lo siguiente: ${ }^{7}$

- Casi ninguna de las Comisiones Colegiadas del Ayuntamiento tiene programas de trabajo y los existentes no tienen congruencia directa con lo plasmado en el Plan Municipal de Desarrollo.

- Se carece de algunos reglamentos municipales básicos y la revisión periódica de los que están operando es tarea excluida de la agenda política del Ayuntamiento. La elaboración de reglamentos municipales se ha estado basando -ya en una proporción considerable de casos- en la adopción de reglamentos aplicados en otras municipalidades. Esta adopción -la mayoría de las veces- se ha realizado de manera desarticulada en relación con las particularidades del municipio.

- El referéndum, el plebiscito y la iniciativa popular están marcados en el reglamento de participación ciudadana, pero no operan.

- La integralidad del Plan Municipal de Desarrollo es parcial, se consideran -hasta cierto punto- las dimensiones económicas y sociales del desarrollo, pero se desatiende -hasta cierto punto- la dimensión política. La revisión de estos planes lleva hacia a la argumentación de que el desarrollo quizá está siendo

${ }^{6}$ Este dato es aproximado por el margen de error en la muestra de estudio y por las limitaciones ordinarias del procedimiento metodológico.

${ }^{7}$ Sólo se incluyen los aspectos manejados en los indicadores que conforman al instrumento de investigación. 
considerado como sinónimo de obra pública. Pero no necesariamente a mayor infraestructura se mejoran las condiciones de desarrollo. La obra pública es importante para la generación de procesos de desarrollo; empero, no es el único elemento. El desarrollo implica la valoración integral de áreas económicas, sociales y políticas.

- La relación entre Plan Municipal de Desarrollo y Presupuesto Municipal de Egresos es débil.

- El cumplimiento del Presupuesto Municipal de Egresos es mínimo. La relación que tiene con el Estado de Origen y Aplicación de Recursos Municipal es baja. No hay congruencia entonces entre el Plan Municipal de Desarrollo, el Presupuesto Municipal de Egresos y el Estado de Origen y Aplicación de Recursos.

- La transferencia de recursos por parte de la federación ha generado también incentivos negativos en los gobiernos municipales. Mientras más recursos reciben, pareciera que menos se esfuerzan en cobrar sus propias entradas de ingresos.

- Los órganos de comunicación social funcionan inadecuadamente. No existen procedimientos ordenados para acceder a la información gubernamental municipal.

- La propuesta sobre redes de política pública pasa inadvertida. No hay interdependencia de actores para establecer objetivos comunes, el gobierno los fija de manera arbitraria. Las pocas prácticas de colaboración social son esporádicas, sin que propiamente se consideren redes de proyecto. La fragilidad de la institucionalidad en el municipio por la débil reglamentación provoca todavía más dificultades para construir redes de políticas públicas estables y sostenibles en el largo plazo.

La reconstrucción de las relaciones entre grupos ciudadanos y gobiernos municipales significa trabajar en los dos lados. Existe un creciente consenso respecto a la necesidad de formar mecanismos que combinen una ciudadanía más activa, capaz de expresar sus demandas, y un gobierno efectivo, con capacidad de responder a esas demandas. La gobernanza es una opción, de visión equilibrada, que no otorga todo a la tecnocracia ni se sumerge en una propuesta anarco-comunitaria.

\subsubsection{Cumplimiento de los gobiernos de los municipios semi-urbanos de Michoacán}

El gobierno de Tarímbaro tiene el mejor cumplimiento de la muestra de estudio (ICG municipal $=0.51)$, seguido del gobierno de Cotija (0.48) y Purépero (0.47). Estos tres resultados están dentro del rango inaceptable. El ICG municipal de Tingambato es el más bajo (0.43): totalmente inaceptable. El ICG $m s u$ es de 0.47 , representa un cumplimiento inaceptable (véase cuadro 4$){ }^{8}$

\footnotetext{
${ }^{8} \mathrm{Al}$ igual que el dato del otro índice, éste también corresponde a una aproximación.
} 
Cuadro 4: Clasificación del ICG msu

\begin{tabular}{|c|c|c|c|c|}
\hline $\begin{array}{c}\text { Cumplimiento } \\
\text { totalmente } \\
\text { inaceptable }\end{array}$ & $\begin{array}{c}\text { Cumplimiento } \\
\text { inaceptable }\end{array}$ & $\begin{array}{c}\text { Cumplimiento } \\
\text { debajo de lo } \\
\text { aceptable }\end{array}$ & $\begin{array}{l}\text { Cumplimiento } \\
\text { aceptable }\end{array}$ & $\begin{array}{c}\text { Cumplimiento } \\
\text { totalmente } \\
\text { aceptable }\end{array}$ \\
\hline 0.20 & \multicolumn{3}{|c|}{0.68} & 1.00 \\
\hline
\end{tabular}

0.47

Fuente: Elaboración propia con base en la investigación documental y de campo.

El 0.53 que falta para que estos gobiernos se aproximen -en la medida de lo posiblea un cumplimiento gubernamental totalmente aceptable $(I C G m s u=1.00)$ se debe a que los habitantes tienen ingresos limitados con respecto al costo que necesitan cubrir para satisfacer necesidades elementales; a que la cobertura en infraestructura educativa media-superior y superior es baja; a que no se ofertan todos los servicios básicos ni tampoco se ha alcanzado cobertura óptima en algunos; a que el personal dedicado a la seguridad pública es insuficiente y poco capacitado. La primera tarea asignada constitucionalmente a los gobiernos locales es ofrecer estos servicios con eficiencia, calidad y puntualidad. Es una actividad exclusiva de ellos. ${ }^{9}$

Los gobiernos de municipios semi-urbanos simplemente han atendido sus funciones ordinarias por inercia. La única innovación en la que han incurrido se halla en el discurso. No hay cambios en lo funcional, estructural y relacional.

\subsection{Correlación entre cumplimiento gubernamental y estilo de gobernar $^{10}$}

Los índices calculados para cada municipio (véase cuadro 5) ayudan a estimar el nivel de correlación que hay entre las áreas de análisis. Hay una correlación positiva fuerte (0.9500) entre cumplimiento gubernamental y gobernanza (véase cuadro 6). Este resultado indica que el bajo cumplimiento de los gobiernos locales se debe en gran medida a la baja gobernanza. Pero el resultado de la correlación debe relativizarse, porque el contexto de los gobiernos de los municipios semi-urbanos es complejo, lo que problematiza el diseño y la puesta en marcha -con intervención ciudadana- de los procesos políticos. No sólo deben preocuparse por las situaciones administrativas y financieras a su interior, sino que deben trabajar en un espacio de intensa lucha por el electorado, lo que propicia que no lleven a cabo algunas tareas (como la recaudación del predial) para elevar sus niveles de cumplimiento, hacerlas puede traer costos cualitativos que se reflejen en la disminución de la simpatía de los ciudadanos. El

9 Sólo se atienden los aspectos manejados en los indicadores.

10 Casi todos los indicadores manejados en el instrumento de estilos de gobernar tienen relación directa con los indicadores usados en el instrumento de cumplimiento gubernamental, muy pocos tienen relación indirecta. Los vínculos que se presenten entre los indicadores son causales. 
esquema de inseguridad en el que actúan -cuando menos- implica que pierdan recursos económicos, pues se minan las bases tributarias al alejarse la inversión. ${ }^{11}$

Cuadro 5: ICG municipal e IEG municipal

\begin{tabular}{|l|c|c|}
\hline Municipio / Variable & ICG municipal & IEG municipal \\
\hline Cotija & 0.48 & 0.37 \\
\hline Purépero & 0.47 & 0.37 \\
\hline Tarímbaro & 0.51 & 0.48 \\
\hline Tingambato & 0.43 & 0.31 \\
\hline
\end{tabular}

Fuente: Elaboración propia.

Cuadro 6: Coeficiente de Correlación de Pearson

\begin{tabular}{|c|c|c|}
\hline Variable & ICG municipal & IEG municipal \\
\hline ICG municipal & 1.0000 & 0.9500 \\
\hline IEG municipal & 0.9500 & 1.0000 \\
\hline
\end{tabular}

Fuente: Elaboración propia.

La posición estratégica que otorga la semi-urbanidad no está siendo aprovechada en Michoacán por los gobiernos locales para optimar sus grados de cumplimiento y para acercarse a una gobernanza. Esto no pone en tela de juicio la posición que brinda lo semi-urbano. Diversos actores sociales, fuera de la institucionalidad formal, la están potenciando ante el incumplimiento gubernamental. El caso Cherán (municipio semi-urbano), ubicado en la región Purépecha, evidencia la formación de redes sociales, sin que se trate propiamente de redes de políticas públicas. En abril de 2011 varias de sus comunidades se rebelaron contra la delincuencia organizada y contra el mismo gobierno municipal. Denunciaron complicidad entre ambos actores. Todo el territorio del municipio fue tomado por varias comunidades, desconociendo cualquier ámbito gubernamental. La gente empezó a regular sus actividades colectivas con la instalación de un gobierno alterno. Este escenario no es nuevo, viene presentándose desde 2007.

No con el mismo grado de intensidad que se presentó en Cherán, se formaron otras redes sociales en varios municipios semi-urbanos de Michoacán. Se trató de los

${ }^{11}$ Es necesario apuntar que existen experiencias sobre gobiernos con diferentes dimensiones territoriales y administrativas que han obtenido resultados aceptables en cuanto a la realización de sus procesos básicos con estilos tradicionales de gobierno. 
Consejos Ciudadanos de Autodefensas, cuyas funciones no se reducían a la seguridad del municipio, sino que entraban ampliamente en la regulación de gran parte de la actividad económica y social. Estos consejos representaron prácticamente gobiernos paralelos. En más de una docena de municipios de Michoacán hubo autodefensas. Casi la mitad de los municipios donde se formaron tienen definición semi-urbana (Buenavista, Tepalcatepec, Salvador Escalante, Parácuaro, Nahuatzen, entre otros). En los municipios urbanos (Los Reyes, Zitácuaro, Apatzingán) y muy urbanos (Uruapan) donde se desenvolvían los consejos se originaron en localidades con características semi-urbanas (La Ruana en Apatzingán, por ejemplo). En mayo de 2014, la mayoría de las autodefensas se constituyó como fuerza de la policía oficial; no obstante, siguen quedando grupos armados fuera de la institucionalidad usando el calificativo de autodefensas.

Las redes sociales formadas al margen de las instituciones -que provocaron la construcción de gobiernos alternos y paralelos- reflejan el bajo cumplimiento gubernamental. Estos tipos de gobiernos informales muestran niveles considerables de ingobernabilidad en los municipios semi-urbanos, pero también permiten identificar las oportunidades que ofrecen los espacios de mediano tamaño para configurar tramas de dinámicas de cooperación social en torno a problemas comunes. Vaya pues, si este tipo de redes se lograran crear dentro del marco institucional y coordinadas de manera efectiva por las organizaciones gubernamentales, sin que éstas tuvieran un papel protagónico, pudieran convertirse en redes de políticas públicas con fuerte posibilidad de solucionar -en la medida de lo posible- los conflictos sustanciales del municipio. Este planteamiento parte de dos supuestos: marco institucional sólido y gobierno altamente representativo.

La delincuencia organizada se infiltró en los gobiernos locales. La delincuencia no formó -en realidad- gobiernos paralelos, operó desde el interior de la municipalidad, su estrategia de inserción estaba en la intimidación agresiva a los presidentes municipales o en postular sus propias planillas para los Ayuntamientos en los procesos electorales usando las etiquetas de los partidos políticos con presencia en el territorio. La existencia de redes de política pública -o cuando menos de redes sociales- hubiera podido disminuir esta situación, puesto que el ejercicio gubernamental se hubiera hecho de manera distribuida, mixta y abierta. Mientras los presidentes municipales concentren todas las decisiones, sometan a todos los equipos de la administración a su manejocontrol, y se miren a sí mismos como únicos conductores del gobierno local, serán blancos directos de la delincuencia organizada.

Aumentar el cumplimiento de las responsabilidades elementales -con participación ciudadana organizada- de los gobiernos de los municipios (en especial de los que tienen categoría semi-urbana) no puede lograrse con estrategias traídas de afuera; de hacerse así, se obtendrían aumentos ficticios, con efectos adversos a la innovación al interior de los gobiernos. Las municipalidades de territorios semi-urbanos no terminarían por consolidarse como gestores del desarrollo y su posición especial -por la fase de transición- no se aprovecharía. El mayor cambio posible sólo puede venir desde adentro, con conexiones adecuadas entre los diferentes niveles de gobiernos, con instituciones estables $\mathrm{y}$, sobre todo, con acciones que extiendan la intervención social de manera 
consistente en el espacio municipal. La gobernanza puede ser el estilo de gobernar que ayude a generar políticas de desarrollo con definición local.

\section{Conclusiones}

El contexto económico, social y político de los municipios semi-urbanos determina la forma de operar de sus gobiernos. Son gobiernos que enfrentan problemáticas mixtas: gestionan -al mismo tiempo- problemas urbanos y rurales. En el proceso de transición de los municipios semi-urbanos se pueden formar condiciones políticas que ayuden a promover interacciones -con cierto grado de estabilidad- entre los diferentes actores que se desenvuelven en el espacio municipal. La operación híbrida de estas municipalidades, aunque implica algunas dificultades, puede aprovecharse como punta para la formación de redes de política pública: gobernar vía gobernanza.

En Michoacán existen 35 municipios con características semi-urbanas, que abarcan el $31 \%$ del total de municipios que conforman a la entidad. Sus gobiernos, de acuerdo con la muestra analizada, siguen funcionando con la visión tradicional: gobernar vía gobernación. Se trata de un estilo donde el protagonismo del actor gubernamental es alto con pocos canales significativos de participación social. El índice de gobernanza es de 0.38 , que equivale a una gobernanza baja.

El índice de cumplimiento gubernamental muestra que estos gobiernos atienden parcialmente la mayoría de sus funciones elementales. La mayor innovación que han hecho se encuentra en el discurso. El valor del índice de cumplimiento es de 0.47 , que representa un cumplimiento inaceptable. La correlación de ambos índices señala que este nivel de cumplimiento se explica por el alto grado de gobernación o por la baja gobernanza (0.9500). No obstante, este resultado es relativo por el contexto violento y político que impera en los municipios estudiados.

Los resultados de los índices indican que la posición estratégica que ofrece la semiurbanidad no está siendo aprovechada por las municipalidades correspondientes. Más bien, la formación de redes sociales -en estos territorios- se está dando al margen de los gobiernos oficiales y se han construido, en algunos casos, gobiernos paralelos. Esta situación sería difícil que se presentara en municipios urbanos y muy urbanos.

\section{Bibliografía}

Aguilar, L. (2010): Gobernanza: el nuevo proceso de gobernar, México, Fundación Friedrich Naumann para la Libertad.

Anderson, D., D. Sweeney y T. Williams (2002): Estadística para administración y economía, México, Thomson Learning.

Cabrero, E. e I. Orihuela (2012): "Índice de Competitividad de las Ciudades de México Versión 2011", en Retos de la competitividad urbana en México, Enrique Cabrero (ed.), México, CIDE, A.C.

Cabrero, E. (2007): "La agenda de políticas públicas en el ámbito municipal: una visión introductoria", en Políticas públicas municipales. Una agenda en construcción, Enrique Cabrero (coord.), México, CIDE, A.C. - Porrúa, pp. 13-47. 
Canto, R. (2012): "Gobernanza y democracia. De vuelta al río turbio de la política", Gestión y Política Pública, XXI-2, México, CIDE, A.C., pp. 333-374.

Cejudo, G., G. Sánchez y D. Zabaleta (2009): "El (casi inexistente) debate conceptual sobre la calidad del gobierno", Política y gobierno, Vol. XVI, No. 1, México, CIDE, A.C., pp. 115-156.

Congreso del Estado de Michoacán (2001): Ley Orgánica Municipal del Estado de Michoacán. Disponible en:

http://docs.mexico.justia.com.s3.amazonaws.com/estatales/michoacan/leyorganica-municipal-del-estado-de-michoacan-de-ocampo.pdf

Consejo Nacional de Población (CONAPO) (2010): Índices de Intensidad Migratoria México-Estados Unidos, México, Secretaría de Gobernación.

Díaz de León, C. G. (2013): "Nueva gestión pública y gobernanza: desafíos en su implementación”, Daena: International Journal of Good Conscience, 8 (1), México, Instituto de Estudios Superiores Penta México, pp. 177-194.

Flamand, L., S. Martínez y A. Hernández (2007): Metodología de cálculo. Índice de desarrollo municipal básico, Tijuana, Colegio de la Frontera Norte.

Herrera, H. y R. Colín (2014): “Capacidades de gestión pública. Análisis de los gobiernos de los municipios semi-urbanos del Estado de Michoacán”, Revista Mexicana de Análisis Político y Administración Pública, Vol. III (1), Guanajuato, División de Derecho, Política y Gobierno, Universidad de Guanajuato, pp. 121-146.

Herrera, H. (2011): Evaluación del desempeño municipal. Propuesta metodológica para los municipios semi-urbanos del Estado de Michoacán, México, INAP, A.C.

Instituto Electoral de Michoacán (2012): Memoria. Procesos electoral ordinario 2011. Proceso electoral extraordinario del Ayuntamiento del Municipio de Morelia 2012, Morelia, IEM.

Instituto Electoral de Michoacán (2015): Proceso electoral ordinario del año 2015. Archivo Documental, Morelia, IEM. Disponible en:

http://iem.org.mx/index.php/archivo-documental/category/249-proceso-electoralordinario-del-ao-2015

Klijn, E-H. (2005): "Las redes de políticas públicas: una visión de conjunto", en La Gobernanza Hoy: 10 Textos de Referencia, Madrid, Instituto Nacional de Administración Pública, pp. 213-244.

Kooiman, J. (2005): “Gobernar en gobernanza”, en La Gobernanza Hoy: 10 Textos de Referencia, Madrid, Instituto Nacional de Administración Pública, pp. 57-81.

LeGalés, P. y M. Tatcher (2005): Les réseaux de politique publique, París, L'Harmattan. López, Ós. (2001): El Ayuntamiento como agente de desarrollo local en el municipio semi-urbano: el caso de Escárcega, Campeche, 1995-2000, Campeche, Colegio Nacional de Licenciados en Administración Pública.

Mayntz, R. (2005): "Nuevos desafíos de la teoría de la gobernanza", en La Gobernanza Hoy: 10 Textos de Referencia, Madrid, Instituto Nacional de Administración Pública, pp. 83-98.

Merino, M. (2007): Para entender el régimen municipal en los Estados Unidos Mexicanos, México, Nostra Ediciones. 
México E. (2013): Índice de Inseguridad Ciudadana y Violencia, México, Centro de Análisis de Políticas Públicas.

Oszlak, Ó. (2013): Gobierno abierto: hacia un nuevo paradigma de gestión pública, Colección de documentos de trabajo sobre e-Gobierno $\mathrm{N}^{\mathrm{o}}$ 5, Red de Gobierno Electrónico de América Latina y el Caribe (Red GEALC), Organización de los Estados Americanos, IDRC-CRDI, Banco Interamericano para el Desarrollo.

Pérez, R. (2007): Agenda municipal Michoacán. Atribuciones, derechos y obligaciones legales de las autoridades y servidores públicos municipales, Morelia, Centro de Investigación y Desarrollo del Estado de Michoacán.

Prats, J. (2005): “Modos de gobernación de las sociedades globales", en La Gobernanza Hoy: 10 Textos de Referencia, Madrid, Instituto Nacional de Administración Pública, pp. 145-172.

Rivera, J. (2014): “Crimen organizado y autodefensas en México: el caso de Michoacán”, Perspectivas, 6, México, Friedrich Ebert Stiftung, pp. 3-16.

Rhodes, R. (2005): "La nueva gobernanza: gobernar sin gobierno", en La Gobernanza Hoy: 10 Textos de Referencia, Madrid, Instituto Nacional de Administración Pública, pp. 99-122.

Sánchez, A., É. Tovar y A. Sánchez (2003): "Evaluación del desempeño de los gobiernos municipales de Jalisco. Hacia una política regional de fortalecimiento municipal", Gestión Municipal, Año 1, 1, Zapopan, CUCEA, Universidad de Guadalajara, pp. 50-67.

Schuschny, A. y H. Soto (2009): Guía metodológica. Diseño de indicadores compuestos de desarrollo sostenible, Santiago de Chile, Naciones Unidas, Comisión Económica para América Latina y el Caribe.

Secretaría de Planeación y Desarrollo Estatal (2005): Nueva Regionalización para la Planeación y Desarrollo del Estado de Michoacán, Morelia, Gobierno del Estado de Michoacán.

Vallès, J. (2002): Ciencia política: una introducción, Barcelona, Editorial Ariel. 